\title{
EFFECTS OF EGTA AND CYTOCHALASIN-B DURING FREEZING AND VITRIFICATION OF IMMATURE AND MATURE BOVINE AND RHESUS MONKEY ( $M$. mulatta) OOCYTES
}

\author{
A.I.Younis ${ }^{1}$, L.Keskintepe ${ }^{2}$, A.A.Simplicio ${ }^{2}$ K. Gould ${ }^{1}$, and B.G.Brackett ${ }^{2}$ \\ ${ }^{1}$ Division of Molecular Medicine, Yerkes Primate Research Center, Emory University, Atlanta, GA \\ $30329,{ }^{2}$ Department of Physiology \& Pharmacology, College of Veterinary Medicine, \\ UGA, Athens, GA 30602, USA
}

Cryopreservation procedures have been shown to be extremely disruptive to the plasma membrane and intracellular organization of mammalian oocyte. Cytochalasin-B (Cyt-B) or EGTA may stabilize oocyte cytoskeletal elements prior to Cryopreservation and make the plasma membrane less rigid and more elastic to avoid injury during the osmotic stresses of freezing. Experiments were conducted to assess the morphological viability and developmental potential of bovine and rhesus monkey oocytes after exposure to Cyt-B or EGTA prior to freezing and vitrification. In the bovine experiments: The methods of oocyte isolation, in vitro maturation (IVM), in vitro fertilization (IVF), and embryonic development (IVC) were as described elsewhere (Biol Reprod. 55:333-339, 1996). All data were analyzed by ANOVA and Chi-square using "StatMost" for Windows. In an initial experiment, a group of immature (GV) oocytes and oocytes after IVM (ova) were randomly selected and pretreated for $5 \mathrm{~min}$ with EGTA (0.1M) or Cyt-B ( $1 \mathrm{mg} / \mathrm{ml}$ ) without cryoprotectant (CPA), and another group were equilibrated for $15 \mathrm{~min}$ with the CPA (1.5 M cthylene glycol mixed with $0.5 \mathrm{M}$ glycerol in PBS) after pretreatment with EGTA or Cyt-B. All oocytes were diluted and/or washed and immediately used for IVM and/or IVF and IVC. No significant differences in cleavage (C) development and blastocyst (B) hatching among treatments in the GV oocytes group. Percentages of early $\mathrm{C}$, morula (M), B, and expanded $\mathrm{B}$ (EB) development ranged $72-82 \%, 53-65 \%, 40-47 \%$ and $25-35 \%$ respectively. Ova treated with EGTA without CPA produced significantly $(\mathrm{P}<.05)$ higher $\mathrm{C}(31 / 41,75 \%)$, M $(48.8 \%)$, B (40\%) and EB (24.4\%) than with Cyt-B. In the slow freezing experiment, a total of $105 \mathrm{GV}$ oocytes and 155 ova were exposed to (a) zero (b EGTA, or (c) Cyt-B before equilibration with $\mathrm{CPA}+0.5$ sucrose in PBS plus $15 \%$ Fetal bovine serum $(\mathrm{PBS} / \mathrm{FBS})$. Gametes were loaded into sterile cryovials, cooled at $2^{\circ} \mathrm{C} / \mathrm{min}$ to $-7^{\circ} \mathrm{C}$, seeded, cooled at $0.3^{\circ} \mathrm{C} / \mathrm{min}$ to $-32^{\circ} \mathrm{C}$, then plunged in $\mathrm{LN}_{2}$. They were thawed in air $(10 \mathrm{sec})$, then warm water $\left(35^{\circ} \mathrm{C}\right)$, and diluted out of CPA in 3 steps $(1,0.5,0.2 \mathrm{M}$ sucrose). Three replicated showed that although many of the frozen-thawed oocytes/ova survived as judged by morphology (range 70-80\%), their developmental potential was severely retarded. C ranged between $0 \%$ to $14.3 \%$. In the vitrification experiment, a total of 135 GV oocytes and 90 ova were grouped as above and vitrified in straws containing a mixture of $3.25 \mathrm{M}$ glycerol and $4.5 \mathrm{M}$ ethylene glycol plus 0.5 sucrose in PBS/FBS. Here, higher $(\mathrm{P}<.05)$ morphological survival rates $(98 \%)$ followed pretreatment with EGTA. However, the developmental potential was very low among all groups ranging between $0 \%$ to $17.7 \%$. In the monkey experiments: The methods of oocyte isolation, IVM and IVF was as described ( Theriogenology 43:362, 1995). A total of 72 GV oocytes and 42 ova were subjected to slow rate freezing and vitrification in groups as described for cow oocytes above. Pretreatment of both GV oncytes or ova with FGTA or C.yt-B prior to freezing or vitrification resulted in $77.6 \%$ morphological survival which was significantly $(\mathrm{P}<.01)$ higher than for the control $(50 \%)$. No differences in fertilization and development were detected among treatment. Percentages of $\mathrm{C}$ to 4-cell stage ranged from 50-67\%. Results suggest prefreeze treatment with EGTA and/or Cyt-B may be useful in enhancement of oocyte/ovum cryopreservation. 